ORIGINAL ARTICLE

\title{
Four-week of local electromyostimulaiton training on fingerboard increases the isokinetic wrist strength and endurance
}

\author{
Dicle Aras ${ }^{1 \mathrm{ABCDE}}$, Selçuk Gül ${ }^{\mathrm{ABBDE}}$, Frrat Akça ${ }^{1 \mathrm{ABDE}}$, Mehmet Gülü̈ ${ }^{1 \mathrm{ABD}}$, Özkan Güler ${ }^{1 \mathrm{ABD}}$, Cemil C. B1ldırcın ${ }^{3 \mathrm{ABE}}$, Erşan \\ Arslan $^{4 \mathrm{ABE}}$, Güney Çetinkaya ${ }^{5 \mathrm{AB}}$ \\ ${ }^{1}$ Ankara University, Turkey \\ ${ }^{2}$ Erzurum Regional Education and Research Hospital, Turkey \\ ${ }^{3}$ Çukurova University, Turkey \\ ${ }^{4}$ Siirt University, Turkey \\ ${ }^{5}$ Akdeniz University, Turkey
}

Authors' Contribution: A -Study design; B -Data collection; C -Statistical analysis; D -Manuscript Preparation; E Funds Collection.

\begin{abstract}
Purpose: $\quad$ Electromyostimulaiton (EMS) has been used for both physical therapy and strength improvements for a few decades. This study aimed to investigate the effects of a four-week local-EMS training performed on a fingerboard (FT) in wrist strength and endurance.

Material: $\quad$ Sixteen physically active, non-climber students were divided into EMS+FT and FT groups. Each group performed the same training program about $25 \mathrm{~min}$ a day, 3 days a week for four weeks. The EMS+FT implementation was performed with a signal width of $260 \mathrm{~ms}$ and a frequency of $60 \mathrm{~Hz}$. Before and after training, isokinetic measurements were collected. The parameters used in the research during flexion and extension at 60 and $180 \%$ sec were; Peak Torque (PT), Peak Torque/Body Weight (PT/BW), and Average Power (AP).

Results: $\quad$ The EMS+FT group showed statistically significant alterations in all of the parameters $(p<0.01$ and $p<0.05)$ except in the left wrist AP during flexion and extension at $180 \%$ sec. However, the FT group showed significant changes in only wright wrist AP during extension at $60 \% \mathrm{sec}$, and wright and left wrist AP during flexion at $180^{\circ} / \mathrm{sec}$, and left wrist PT during extension at $180^{\circ} / \mathrm{sec}$.

Conclusions: Accordingly, it could be inferred that FT done by using EMS for four weeks improve the isokinetic wrist strength and endurance significantly. Muscular fitness has an essential role in climbing performance, and this study points that EMS trainings on fingerboard could be used to enhance the climbing performance.

Keywords: electrical contraction, isokinetic forearm endurance, isokinetic forearm strength, sport climbing, fingerboard.
\end{abstract}

\section{Introduction}

Electromyostimulaiton (EMS) has been used for both physical therapy [1] and strength improvements for a few decades [2-4].The principle of EMS is to gain muscle strength through pulsed, repetitive electrical contractions $[5,6]$ by recruiting more motor units and muscle fibers which activated with high threshold [7]. Main objectives of using this kind of equipment in sport is reported to shorten the training session, and to specialize in targeted aims for better performance [8]. In recent years, many reviews have examined the effects of voluntary contraction with or without using EMS, and EMS training alone on muscular strength, muscular endurance, power, jumping, balance, speed, and performance not only in sedentary adults also in athletes [4, 5, 8-11]. Some general information from these studies could be summarized that; EMS training enhances both muscle mass and function without any change in body fat $[12,13]$, using EMS is effective to prevent muscle loss during the rehabilitation phase [5], and more research is needed to determine how effective is only EMS training or EMS training + voluntary contraction for muscle strength development. While in some studies it was found that EMS training

\footnotetext{
๑) Dicle Aras, Selçuk Gül, Fırat Akça, Mehmet Gülü, Özkan Güler, Cemil C. Bıldırcın, Erşan Arslan, Güney Çetinkaya, 2020
} doi:10.15561/20755279.2020.0301 provides equally or even more enhancements in gaining strength [3, 14], others reported voluntary contraction's effectiveness $[4,15]$. These articles also show that using EMS could be varied as locally and whole body. While whole body EMS allows stimulating several muscle groups concurrently on a wide electrode area, local EMS interventions activate a single or small number of specific muscles. Another suggestion is that while currents with high frequency are used to gain maximal muscle strength, low frequency currents are used in order to induce muscle endurance [8].

It is suggested that to control the wrist efficiently and optimal use of wrist muscles are critical for both daily activities and sports [16]. Being the most preferred discipline of rock climbing, sport climbing has become very popular both as a competitive and recreational activity [17]. As in all sport branches, special training is needed also in sport climbing. Due to the complex structure of sport climbing [18], athletes and sedentary people who climb recreationally need to improve their grip performance [19]. Both finger flexors' isometric strength and endurance are evaluated as the key factor of bouldering [20] and lead climbing performances [21] in sport climbing [22]. According to [23] climbers spend $36.3 \%$ of the total time statically during climbing. A fingerboard, also known as a hangboard, is one of the sport 
specific strength training equipment to advance isometric finger strength in climbing. Some studies observed about $21.5 \%$ increase in finger strength after four weeks of fingerboard training [24]. Finger flexors' isometric contraction is believed as the most used type of muscle activation during climbing [25], and fingerboard trainings (FT) provide climbers isometric training opportunities on several different artificial grips [26].

The aim of the present study is to investigate the influences of four week local EMS training on wrist muscular strength and endurance. To our knowledge, this is the first study comparing the isokinetic strength and endurance responses between EMS+FT and FT alone in sport climbing. In order to achieve this goal, local EMS electrodes were placed on forearm flexors because of the fact that a fingerboard is used only with arms.

\section{Material and Methods}

Participants. A total number of 16 physically active, non-climber sport sciences students, who had attended a regular physical activity program for at least six months prior to this research, participated in the study voluntarily. Subjects were randomly divided into fingerboard training group (FT: 4 males and 4 females, the mean age $22.75 \pm$ 1.83 years, body height $173.63 \pm 9.84 \mathrm{~cm}$, body weight $59.50 \pm 7.75 \mathrm{~kg}$ ) and EMS+fingerboard training group (EMS+FT: 5 males and 3 females, mean age $22.38 \pm 2.45$ years, body height $171.00 \pm 8.96 \mathrm{~cm}$, body weight 64.75 $\pm 14.69 \mathrm{~kg}$ ). Both groups did not take a part in any other exercise program for the four weeks during the study. The exclusion criteria were having any previous or current musculoskeletal injuries in upper body extremities. All subjects were informed about the study risks and benefits, and after familiarization, each participant was given a written informed consent form. This study was performed in accordance with the ethics of World Medical Association (Declaration of Helsinki, code DoH-Oct2013), and was approved by Ankara University Ethical Committee on Human Research (01/13).

Study design. This randomized controlled trial aims to investigate the effects of four-week local EMS training performed on a fingerboard on wrist muscular strength and endurance. To achieve this goal, a total of four EMS electrodes were placed on the flexor digitorum superficialis (FDS) muscle, two on the right and two on the left arm. Both FT and EMS+FT groups completed the same training program about 25 minutes a day, three days per week for four weeks. All fingerboard trainings were performed between 4 and $6 \mathrm{pm}$ on non-consecutive days, and subjects were asked to come to the training as fully rested. Two days earlier and two days after the four-week period of the study, participants attended an isokinetic wrist muscle strength and endurance test.

Procedures. Training process. Participants visited the performance laboratory for the first time for familiarization, and they were informed about the study design. The fingerboard and its biggest jug hold used in the current study were shown. They were taught how to grip the hold and how to endure hanging on at different angles of elbow. The jug hold allowed participants to wrap it with their index, middle, ring and pinky fingers. While thumb was holding the jug with the distal interphalangeal joint, the other fingers were wrapping it with $90^{\circ}$ of proximal interphalangeal joint. Owing to the fact that rock climbing requires feet to release from wall during climbing, all fingerboard trainings were performed with the feet were in the air.

All subjects were also taught about the EMS implementation. The EMS practice was performed with a Bosch TENS+EMS Dual Therapy device (Stuttgart. GERMANY) with a signal width of $260 \mathrm{~ms}$ and a frequency of $60 \mathrm{~Hz}$. The EMS device was fixed subject's waist, and its four electrodes were placed on forearms of both right and left upper extremities. Two of the electrodes located on flexor digitorum superfacialis muscle of the right arm and other two on the left. Subjects performed another trial with using EMS.

Table 1. The angle of the elbow and hanging and resting times of the training protocol.

\begin{tabular}{lll}
\hline $\begin{array}{l}\text { Angle of the } \\
\text { elbow }\end{array}$ & $\begin{array}{l}\text { Hanging time } \\
\text { (sec) }\end{array}$ & $\begin{array}{l}\text { Resting time } \\
\text { (sec) }\end{array}$ \\
\hline $180^{\circ}$ & 15 & 15 \\
$90^{\circ}$ & 15 & 15 \\
$45^{\circ}$ & 15 & 60 \\
$180^{\circ}$ & 20 & 15 \\
$90^{\circ}$ & 15 & 15 \\
$45^{\circ}$ & 10 & 60 \\
$180^{\circ}$ & 25 & 15 \\
$90^{\circ}$ & 15 & 15 \\
$45^{\circ}$ & 5 & 180 \\
\hline
\end{tabular}

Total time for one circle: $8.40 \mathrm{~min}$

Table 1 shows one circle of the training session. All participants performed one circle of training without EMS and another one by using EMS on their first visit. After finishing familiarization session, participants were randomly divided into fingerboard training group, in which they performed isometric fingerboard training, and EMS+FT group (EMS+FT) in which they practiced the same training with using EMS. The number of the training circle was two for the first two weeks of the study, and it was increased to four for the last two weeks of the study. Each participants had a 10-minute warm-up, and a 5-minute time resting time procedure before every training session. Warm-up procedure contained of $5 \mathrm{~min}$ of jogging and $5 \mathrm{~min}$ of upper arm stretching exercises.

Isokinetic tests. Participants' isokinetic muscular strength and endurance measurements were tested on isokinetic machine (System 4 PRO model, Biodex Medical Systems, Shirley, NY, USA) on wrist joint during flexion and extension at $60 \% \mathrm{~s}$ and $180 \% \mathrm{~s}$ angular velocities. For 5 repetitions at $60 \%$ angular velocity Peak torque (PT, N.m), peak torque/body weight (PT/BW, \%) and average power (AP, W) were collected for muscle strength, and same parameters were also collected for 10 repetitions at 
$180 \%$ for muscle endurance. The resting period between tests was 30 seconds. Before testing, participants were told to warm up at an arm ergometer for four minutes at between 60-80 rpm. In four minutes of resting time after the warming up, the test protocol was started. Pre-tests were taken two days before the study period, and posttests were recorded in two days right after the study was finished.

Statistical analyses. In the current study, IBM SPSS Statistics (Version 23 for Windows; IBM, Armonk, NY, USA) was used for statistical data analyses. Firstly, the distribution of data was tested by Shapiro Wilk to determine the parametric or nonparametric data analyses. In accordance with the distribution of the data Paired Sample t-Test or Wilcoxon Test was chosen for pre and post-test analyses, and Independent Paired t-Test or MannWhitney U Test was used for inter group analyses. Alpha value was set at 0.05 for all of the statistical analyses.

\section{Results}

Pre and post-tests of wrist isokinetic strength and endurance measurements both at $60 \%$ and $180 \%$ are presented in Table 2 and 3 respectively.

Table 2 shows that using EMS while fingerboard training increases the wrist muscle strength significantly. In EMS+FT group, all the PT parameters recorded at $60 \%$, developed from 18.77 to $31.57 \%$. The percentage of the alterations observed in PT/BW was between 18.61 - $33.02 \%$, and the highest change was seen in right wrist AP parameter for EMS+FT group $(81.62 \%)$.

When examining the Table 3 , it could be seen that only significant increases observed in the FT group were in the right and left wrist AP parameters during flexion $(\mathrm{p}<0.01$ and $\mathrm{p}<0.05$ ), and in left wrist extension PT parameter at $180 \% \mathrm{~s}(\mathrm{p}<0.01)$. However, the EMS+FT group showed statistically significant changes in all of the parameters except in the left wrist AP parameters during flexion and extension at $180 \%$ s. The alteration rate was from 17.64 to $42.20 \%$ in PT, 20.98 to $41.60 \%$ in PT/BW. Besides, similarly to the result at $60 \% \mathrm{~s}$ the highest change observed in right wrist AP parameter $(81.46 \%)$.

Another substantial finding of the research was that both groups showed enhancements in all of the strength and endurance parameters, even though these alterations were mainly not significant in the FT group generally.

\section{Discussion}

The purpose of the current study was to examine the effects of four-week local EMS training on isokinetic muscle strength and endurance in wrist, and compare it with fingerboard training. It is considered that isometric training might induce more muscle force comparing with dynamic training [27], and isometric strength and endurance are more substantial for climbing [28]. It was reported that climbers' isometric contraction time ratio was 4:1 compared with resting time [29]. However, to transfer the obtained isometric strength and endurance to all types of movements in climbing requires to perform the isokinetic training at different angles of the targeted joint. According to Thompson et al. [30] an isometric training provides strength improvements only in $\pm 15^{\circ}$ of the selected joint. Some studies about climbing also reported that different elbow or shoulder angles cause unequal strength production in finger flexors [31, 32]. Thus, in the present study, different angles of elbow were chosen to adapt the wrist to be able to generate strength in

Table 2. Isokinetic strength values and their mean differences obtained from pre and post-tests at $60 \% \mathrm{~s}$ for both right and left wrists during flexion and extension.

\begin{tabular}{|c|c|c|c|c|c|c|c|c|}
\hline \multirow{2}{*}{ Parameters } & \multicolumn{2}{|c|}{ FT group } & \multirow[b]{2}{*}{$\%$} & \multirow[b]{2}{*}{ Sig. } & \multicolumn{2}{|l|}{ EMS+FT group } & \multirow[b]{2}{*}{ Sig. } & \multirow[b]{2}{*}{$\%$} \\
\hline & Pre-test & Post-test & & & Pre-test & Post-test & & \\
\hline \multicolumn{9}{|c|}{ Right wrist during flexion at $60 \% \mathrm{sec}$} \\
\hline PT (N.m) & $36.86 \pm 11.23$ & $45.11 \pm 20.18$ & 22.38 & .094 & $39.74 \pm 8.31$ & $50.30 \pm 13.53$ & $.038^{*}$ & 26.57 \\
\hline PT/BW (\%) & $63.44 \pm 18.06$ & $75.63 \pm 27.40$ & 19.22 & .089 & $62.20 \pm 10.42$ & $76.79 \pm 14.27$ & $.048 *$ & 23.46 \\
\hline $\mathrm{AP}(\mathrm{W})$ & $13.75 \pm 6.21$ & $22.86 \pm 12.18$ & 66.25 & .123 & $15.78 \pm 4.68$ & $28.66 \pm 14.82$ & $.012 *$ & 81.62 \\
\hline \multicolumn{9}{|c|}{ Left wrist during flexion at $60 \% \mathrm{sec}$} \\
\hline PT (N.m) & $40.26 \pm 16.27$ & $41.83 \pm 14.43$ & 3.90 & .779 & $38.68 \pm 14.99$ & $50.89 \pm 16.29$ & $.001^{* *}$ & 31.57 \\
\hline PT/BW (\%) & $67.64 \pm 18.88$ & $69.77 \pm 20.59$ & 3.15 & .624 & $58.48 \pm 15.83$ & $77.79 \pm 17.14$ & $.001 * *$ & 33.02 \\
\hline $\mathrm{AP}(\mathrm{W})$ & $16.93 \pm 8.89$ & $18.53 \pm 9.10$ & 9.45 & .236 & $18.08 \pm 8.74$ & $25.13 \pm 8.52$ & $.018 *$ & 38.99 \\
\hline \multicolumn{9}{|c|}{ Right wrist during extension at $60 \% / \mathrm{sec}$} \\
\hline PT (N.m) & $25.80 \pm 13.41$ & $28.58 \pm 10.08$ & 10.76 & .208 & $23.71 \pm 7.75$ & $29.13 \pm 8.90$ & $.031^{*}$ & 22.86 \\
\hline PT/BW (\%) & $43.35 \pm 17.86$ & $47.81 \pm 12.16$ & 10.29 & .197 & $36.13 \pm 7.10$ & $45.00 \pm 9.25$ & $.024 *$ & 24.55 \\
\hline $\mathrm{AP}(\mathrm{W})$ & $12.28 \pm 4.90$ & $16.21 \pm 6.88$ & 32.00 & $.040 *$ & $12.15 \pm 4.23$ & $15.89 \pm 5.72$ & $.031^{*}$ & 30.78 \\
\hline \multicolumn{9}{|c|}{ Left wrist during extension at $60 \% / \mathrm{sec}$} \\
\hline PT (N.m) & $25.74 \pm 11.23$ & $28.75 \pm 9.13$ & 11.69 & .194 & $26.48 \pm 8.93$ & $31.45 \pm 11.77$ & $.005^{* *}$ & 18.77 \\
\hline PT/BW (\%) & $43.18 \pm 14.23$ & $48.39 \pm 11.03$ & 12.07 & .244 & $40.56 \pm 8.90$ & $48.11 \pm 13.47$ & $.006 * *$ & 18.61 \\
\hline AP (W) & $12.75 \pm 6.55$ & $14.78 \pm 4.26$ & 15.92 & .214 & $15.15 \pm 6.15$ & $18.13 \pm 7.53$ & $.004^{* *}$ & 19.67 \\
\hline
\end{tabular}

Note: PT: Peak torque, PT/BW: Peak torque/body weight, AP: Average power. ${ }^{*} \mathrm{p}<0.05 ;{ }^{* *} \mathrm{p}<0.01$ 
Table 3. Isokinetic endurance values and their mean differences obtained from pre and post-tests at $180 \% \mathrm{~s}$ for both right and left wrists during flexion and extension.

\begin{tabular}{|c|c|c|c|c|c|c|c|c|}
\hline \multirow{2}{*}{ Parameters } & \multicolumn{3}{|c|}{ FT group } & \multicolumn{3}{|c|}{ EMS+FT group } & \multirow[b]{2}{*}{ Sig. } & \multirow[b]{2}{*}{$\%$} \\
\hline & Pre-test & Post-test & $\%$ & Sig. & Pre-test & Post-test & & \\
\hline \multicolumn{9}{|c|}{ Right wrist during flexion at $180 \%$ sec } \\
\hline PT (N.m) & $29.16 \pm 10.81$ & $36.69 \pm 16.88$ & 25.82 & .123 & $25.69 \pm 5.61$ & $36.53 \pm 6.43$ & $.001 * *$ & 42.20 \\
\hline PT/BW (\%) & $49.90 \pm 16.16$ & $61.24 \pm 21.52$ & 22.73 & .223 & $40.38 \pm 8.55$ & $57.18 \pm 5.62$ & $.001 * *$ & 41.60 \\
\hline $\mathrm{AP}(\mathrm{W})$ & $12.70 \pm 6.56$ & $19.89 \pm 10.19$ & 56.61 & $.010 * *$ & $12.89 \pm 5.13$ & $23.39 \pm 8.27$ & $.012^{*}$ & 81.46 \\
\hline \multicolumn{9}{|c|}{ Left wrist during flexion at $180 \% \mathrm{sec}$} \\
\hline PT (N.m) & $30.45 \pm 16.10$ & $34.11 \pm 15.08$ & 12.02 & .208 & $29.53 \pm 9.88$ & $34.74 \pm 8.60$ & $.017^{*}$ & 17.64 \\
\hline PT/BW (\%) & $50.74 \pm 19.83$ & $56.80 \pm 18.97$ & 11.94 & .230 & $44.88 \pm 7.19$ & $52.84 \pm 8.43$ & $.039 *$ & 17.74 \\
\hline $\mathrm{AP}(\mathrm{W})$ & $13.94 \pm 8.30$ & $18.94 \pm 10.75$ & 35.87 & $.025^{*}$ & $18.33 \pm 8.42$ & $22.23 \pm 9.05$ & .141 & 21.28 \\
\hline \multicolumn{9}{|c|}{ Right wrist during extension at $180 \%$ sec } \\
\hline PT (N.m) & $19.75 \pm 7.70$ & $25.65 \pm 17.98$ & 29.87 & .123 & $17.43 \pm 3.96$ & $22.93 \pm 4.86$ & $.003^{* *}$ & 31.55 \\
\hline PT/BW (\%) & $33.50 \pm 9.18$ & $42.06 \pm 23.91$ & 25.55 & .123 & $26.99 \pm 2.38$ & $35.69 \pm 5.44$ & $.004^{* *}$ & 32.23 \\
\hline $\mathrm{AP}(\mathrm{W})$ & $12.81 \pm 4.21$ & $16.65 \pm 9.28$ & 29.98 & .118 & $11.36 \pm 3.15$ & $16.83 \pm 7.01$ & $.037 *$ & 48.15 \\
\hline \multicolumn{9}{|c|}{ Left wrist during extension at $180 \% / \mathrm{sec}$} \\
\hline PT (N.m) & $18.91 \pm 8.06$ & $22.31 \pm 7.75$ & 17.98 & $.050^{*}$ & $19.64 \pm 5.09$ & $23.79 \pm 7.54$ & $.016^{*}$ & 21.13 \\
\hline PT/BW (\%) & $31.78 \pm 9.79$ & $37.75 \pm 10.28$ & 18.79 & .099 & $30.51 \pm 5.46$ & $\begin{array}{l}36.91 \pm \\
10.12\end{array}$ & $.021 *$ & 20.98 \\
\hline $\mathrm{AP}(\mathrm{W})$ & $12.03 \pm 5.13$ & $13.09 \pm 2.89$ & 8.81 & .263 & $15.36 \pm 6.45$ & $18.08 \pm 8.69$ & .173 & 17.71 \\
\hline
\end{tabular}

Note: PT: Peak torque, PT/BW: Peak torque/body weight, AP: Average power. ${ }^{*} \mathrm{p}<0.05 ;{ }^{*} \mathrm{p}<0.01$

different angles.

It is well known that when the angle of the climbed surface increases, most of the body weight is moving by small muscle groups in the upper extremities [28]. This change is about $44 \%$ as the climbing surface alters $10^{\circ}$ from vertical to overhanging [33]. Since forearm muscles are the main reason of fatigue and lactate concentration $[29,34]$, and forearm muscle strength has a substantial role during climbing [35], EMS electrodes were placed on forearm finger flexors in the present study. Flexor digitorum superfacialis and profundus are considered as the most effective muscles in climbing [28]. The reason of choosing the hold with the biggest grip on the fingerboard was to prevent subjects from injury. The wrist strength is specifically investigated in some studies. Chu $\mathrm{E}$ et al. [16] sought the effects of 6 weeks of resistance training on motor control and wrist strength, and found that both motor control abilities and wrist strength improve after six weeks of training. Schweizer et al. [25] investigated the relationship between some strength parameters and climbing performance and reported that the only predictor of the performance in sport climbing was wrist flexion. In the present study EMS+FT group showed from 18.77 to $31.57 \%$ changes on PT, $18.61-33.02 \%$ on $\mathrm{PT} / \mathrm{BW}$, and 19.67 to $81.62 \%$ on AP parameters during wrist flexion and extension at $60 \% \mathrm{sec}$. The observed changes in muscular endurance during flexion and extension at $180 \% \mathrm{sec}$ in wrist were from 17.64 to 42.20 on PT, 20.98 to 41.60 on $\mathrm{PT} / \mathrm{BW}$, and 17.71 to $81.46 \%$ on average power. Increase in muscular endurance of elite climbers is considered due to improved local vasodilation capacity, reoxygenation during resting and deoxygenation during isometric contractions in the literature [36]. Besides, a rise in arterial blood pressure is also thought to be a factor to enhance the isometric contraction of hand [37]. The positive changes observed both in strength and endurance values in the current study might be occurred by the same mechanisms.

Neural adaptations that occur with both muscle activation and increased electromyographic activity could be seen mainly after short EMS training periods $[9,38]$. In the present study, positive changes to EMS+FT training on isokinetic muscle strength and endurance were seen in four weeks. Besides, along with significant changes observed in EMS+FT group, the FT group also showed statistically significant or insignificant positive alterations. They increased PT between 3.90 - 25.82 \%, PT/BW 3.15 $19.22 \%$, and AP $9.45-66.25 \%$ at $60 \%$ sec. Enhancements derived from $180 \%$ sec were between $12.02-29.87 \%$ for PT, $11.94-25.55 \%$ for PT/BW, and $8.81-56.61 \%$ for AP. Similarly to EMS+FT group the highest alterations were observed in average power values. These outcomes are in line with the literature. A research, in which isometric, isotonic, and isokinetic training procedures were compared, showed that most increase in strength was observed after isometric training implementation [39], similar study was performed by Medernach et al. (2015) [26]. Researchers investigated the effects of 4-week fingerboard training with 3 sessions per week in boulderers. Even though their subjects consisted of highly advanced climbers, they found significant changes on grip strength and endurance level in competitive boulderers.

Several studies examined the effects of EMS training on some extremities and body parts other than wrist. For 
instance, Herrero et al. [14] compared the effects of four weeks weight+EMS training with weight training alone on knee strength, and found more increase in weight+EMS group than weight training group alone $(40.2 \%$ and $31.4 \%$, respectively). In another study, effects of EMS, plyometric training, EMS+plyometric training were compared on sprint time, jumping ability, and maximal isometric strength values, and researchers found that EMS+plyometric training significantly increases jumping height and sprint performance. Similarly, Maffiuletti et al. [9] demonstrated enhancements on knee extensor strength and squat jump performance in basketball players after four weeks of EMS training. Furthermore, EMS (9.1 $\%$ ), or EMS+plyometric training $(16.3 \%)$ provides enhancement on maximal strength [40]. Brocherieet al. [41] investigated the effects of short-term using of EMS (30 muscle contractions with 4 second duration), and found improvements on isokinetic strength and short skating performance in ice hockey players after three weeks of training. Using EMS on knee extensor, plantar flexor, and gluteus muscles showed significant developments on power and muscle strength in Rugby players after 12 weeks [38]. Silinskas et al. [42] applied EMS on calf muscles and found about $6 \%$ increase in right muscle MVC in healthy men, and about $5 \%$ improvement in 10-m sprint time in trained athletes, only after 10 sessions of training in three weeks. All these studies and many others demonstrated positive influences of using EMS, and the gains observed in strength and some performance parameters are similar to the changes reached in the present study.

The results derived from the current study are significant not only for the performance but also for injury prevention for climbers, due to the fact that the injuries on wrist usually depend on the lack of strength and joint control in wrist [43]. Josephsen et al. [44] found significant relationship with resistance training and decrease in injury in boulderers. Some authors [2] reported that most injuries are observed in hand and fingers in rock climbing $[26,44,45]$. Therefore, improving the muscle strength and endurance on these parts of the body is crucial.

A same or similar study could be performed with any level of rock climbers including advanced or elite athletes. According to Filipovic et al. [8] even the elite level athletes should not change the number of training sessions to improve their strength by using EMS. Congruently, reported 30 to 40 percent of strength improvement in trained athletes after using EMS. Besides, as climbing involves grips in different directions, future studies could investigate the effects of wrist training at different directions such as flexion-extension, pronationsupination, and ulnar-radial deviation. It is reported that strength improves with direction-based strength and joint training [16]. In the present study, strength training was performed in vertical axis and on a jug hold for the subjects consisted of non-climber individuals. Different grips for advanced or elite climbers could provide them better strength development at different joint angles, or using jug holds with different directions could be helpful with transferring the strength to climbing performance in beginners.

\section{Conclusion}

Although the participants were physically active individuals, training on a sport specific plate, such as fingerboard, improved their wrist strength and endurance in the both EMS+FT and FT groups. Apart from this, the EMS+FT group showed significant increases in almost all of the parameters. Accordingly, it could be inferred that fingerboard trainings done with EMS during three days a week for four weeks improve the wrist strength and endurance significantly. Being one of the basic components of rock climbing, muscular fitness has an essential role in climbing performance. This study points that EMS trainings on fingerboard could be used to enhance the climbing performance. Future studies could include measuring the isokinetic strength and endurance of muscle groups not placed with EMS in order to understand whether EMS is effective only in the muscle groups in which it is placed. In order to compare the difference between only climbing training to fingerboard training with EMS, a similar study could be employed with another experimental group who climbs only. Additionally, the more functional information about the effects of EMS could be given using EMS during climbing training.

\section{Conflict of interest}

The authors of the article declare that there is no conflict of interest. 


\section{References}

1. Jee YS. The efficacy and safety of whole-body electromyostimulation in applying to human body: based from graded exercise test. J Exerc Rehabil. 2018; 14(1): 49-57. https://doi.org/10.12965/jer.1836022.011

2. Kots JM, Chwilon W. Das muskelkrafttraining mit der method der elektromyostimulation. Leistungssport [Muscle strength training with the method of electromyostimulation]. In: Andrianowa GG, Koz JM, Martjanow WA, Chwilon WA. (Eds). Die Anwendung der Elektrostimulation für das Training der Muskelkraft [The use of electrostimulation for training muscle strength]. Leistungssport, 4(2); 1974. (In Deutsch)

3. Laughman RK, Youdas JW, Garrett TR, Chao EYS. Strength changes in the normal quadriceps femoris muscle as a result of electrical stimulation. Physical therapy, 1983; 63: 494. https://doi.org/10.1093/ptj/63.4.494

4. Requena Sanchez B, Padial Puche P, GonzalezBadillo JJ. Percutaneous electrical stimulation in strength training: an update. Journal of Strength and Conditioning Research, 2005; 19(2): 438-448. https://doi.org/10.1519/13173.1

5. Bax L, Staes F, Verhagen A. Does neuromuscular electrical stimulation strengthen the quadriceps femoris? Sports Med. 2005; 35(3): 191-212. https://doi.org/10.2165/00007256-200535030-00002

6. Van Buuren F, Horstkotte D, Mellwig KP, Frund A, Vlachojannis M, Bogunovic N, etal.Electrical Myostimulation (EMS) Improves Glucose Metabolism and Oxygen Uptake in Type 2 Diabetes Mellitus Patients-Results from the EMS Study. Diabetes Technol Ther. 2015; 17(6): 413-419. https://doi.org/10.1089/dia.2014.0315

7. Enoka RM. Activation order of motor axons in electrically evoked contractions. Muscle Nerve. 2002; 25(6): 763-774. https://doi.org/10.1002/mus.10117

8. Filipovic A, Kleinoder H, Dormann U, Mester J. Electromyostimulation-a systematic review of the effects of different electromyostimulation methods on selected strength parameters in trained and elite athletes. Journal of Strength and Conditioning Research, 2012; 26(9): 2600-2614. https://doi.org/10.1519/JSC.0b013e31823f2cd1

9. Maffiuletti NA, Cometti G, Amiridis IG, Martin A, Pousson M, Chatard JC. The effects of electromyostimulation training and basketball practice on muscle strength and jumping ability. Int J Sports Med. 2000; 21(6): 437-443. https://doi.org/10.1055/s-2000-3837

10.Paillard T. Combined application of neuromuscular electrical stimulation and voluntary muscular contractions. Sports Med. 2008; 38(2): 161-177. https://doi.org/10.2165/00007256-200838020-00005

11.Adams V. Electromyostimulation to fight atrophy and to build muscle: facts and numbers. $J$ Cachexia Sarcopenia Muscle. 2018; 9(4): 631-634. https://doi.org/10.1002/jcsm.12332

12.Kemmler W, Teschler M, Weissenfels A, Bebenek $\mathrm{M}$, von Stengel S, Kohl $\mathrm{M}$, et al. Whole-body electromyostimulation to fight sarcopenic obesity in community-dwelling older women at risk. Results of the randomized controlled FORMOsA-sarcopenic obesity study. Osteoporos Int. 2016; 27(11): 3261-3270. https://doi.org/10.1007/s00198-016-3662-z

13.Kemmler W, Weissenfels A, Teschler M, Willert S, Bebenek M, Shojaa M, et al. Whole-body electromyostimulation and protein supplementation favorably affect sarcopenic obesity in community- dwelling older men at risk: the randomized controlled FranSO study. Clin Interv Aging. 2017; 12: 1503-1513. https://doi.org/10.2147/CIA.S137987

14.Herrero AJ, Martín J, Martín T, Abadía O, Fernández B, García-López D. Short-term effect of strength training with and without superimposed electrical stimulation on muscle strength and anaerobic performance. A randomized controlled trial. Part I. Journal of Strength and Conditioning Research, 2010; 24(6): 1609-1615. https://doi.org/10.1519/JSC.0b013e3181dc427e

15.Currier D, Mann R. Muscular strength development by electrical stimulation in healthy individuals. Phys Ther. 1983; 63(6): 915-921. https://doi.org/10.1093/ptj/63.6.915

16.Chu E, Kim Y-S, Hill G, Kim YH, Kim CK, Shim JK. Wrist Resistance Training improves motor control and strength. Journal of Strength and Conditioning Research, 2018; 32(4): 962-969. https://doi.org/10.1519/JSC.0000000000002019

17.Backe S, Ericson L, Janson S, Timpka T. Rock climbing injury rates and associated risk factors in a general climbing population. Scand J Med Sci Sports. 2009; 19(6): 850-856. https://doi.org/10.1111/j.1600-0838.2008.00851.x

18.Aras D, Kitano K, Phipps AM, Enyart MR, Akça F, Koceja $\mathrm{DM}$, et al. The comparison of postural balance level between advanced sport climbers and sedentary adults. International Journal of Applied Exercise Physiology, 2018; 7(3): 1-9.

19.Anderson ML, Anderson ML, Sanders A. An innovative hangboard design to improve finger strength in rock climbers. Procedia Engineering, 2016; 147: 269-274. https://doi.org/10.1016/j.proeng.2016.06.276

20.Michailov M, Mladenov L, Schöffl V. Anthropometric and strength characteristics of world-class boulderers. Med Sport, 2009; 13(4): 231-238. https://doi.org/10.2478/v10036-009-0036-z

21.Baláš J, Pecha O, Martin AJ, Cochrane D. Hand-arm strength and endurance as predictors of climbing performance. European Journal of Sport Science, 2012; 12(1): 16-25. https://doi.org/10.1080/17461391.2010.546431

22.Fanchini M, Violette F, Impellizzeri FM, Maffiuletti NA. Differences in climbing-specific strength between boulder and lead rock climbers. Journal of Strength and Conditioning Research, 2013(2); 27: 310-314. https://doi.org/10.1519/JSC.0b013e3182577026

23.Billat V, Palleja P, Charlaix T, Rizzardo P, Janel N. Energy specificity of rock climbing and aerobic capacity in competitive sport rock climbers. J Sports Med Phys Fitness, 1995; 35(1): 20-24

24.Anderson M, Anderson M. A novel tool and training methodology for improving finger strength in rock climbers. Procedia Engineering, 2015; 112: 491-496. https://doi.org/10.1016/j.proeng.2015.07.230

25.Schweizer A, Furrer M. Correlation of forearm strength and sport climbing performance. Isokinetics and Exercise Science, 2007; 15(3): 211-216. https://doi.org/10.3233/IES-2007-0275

26.Medernach JP, Kleinöder H, Lötzerich HH. Fingerboard in competitive bouldering: Training effects on grip strength and endurance. Journal of Strength and Conditioning Research, 2015; 29(8): 2286-2295. https://doi.org/10.1519/JSC.0000000000000873

27.Duchateau J, Hainaut K. Isometric or dynamic training: differential effects on mechanical properties of a human muscle. J Appl Physiol Respir Environ Exerc Physiol. 1984; 56(2): 296-301. 
https://doi.org/10.1152/jappl.1984.56.2.296

28.MacLeod D, Sutherland D, Buntin L, Whitaker A, Aitchison T, Watt I, et al. Physiological determinants of climbing-specific finger endurance and sport rock climbing performance. J Sports Sci. 2007; 25(12): 1433-1443. https://doi.org/10.1080/02640410600944550

29.Michailov M. Workload characteristic, performance limiting factors and methods for strength and endurance training in rock climbing. Med Sport, 2014; 18(3): 97-106.

30.Thompson WR, Bushman BA, Desch J, Kravitz L. ACSM'S Resources for the personal trainer. Champaign (IL): Lippincott Williams \& Wilkins; 2010.

31.Grant S, Shields C, Fitzpatrick V, Loh MW, Whitaker A, Watt I, et al. Climbing-specific finger endurance: a comparative study of intermediate rock climbers, rowers and aerobically trained individuals. Journal of Sports Sciences, 2003; 21(8): 621-630. https://doi.org/10.1080/0264041031000101953

32.Baláš J, Panáčková M, Kodejška J, Cochrane JD, Martin JA. The role of arm position during finger flexor strength measurement in sport climbers. International Journal of Performance Analysis in Sport, 2014; 14(2): 345-354. https://doi.org/10.1080/24748668.2014.11868726

33.Noé F, Quaine F, Martin L. Influence of steep gradient supporting walls in rock climbing: biomechanical analysis. Gait \& Posture, 2001; 13(2): 86-94. https://doi.org/10.1016/S0966-6362(00)00098-9

34.Watts PB, Jensen RL, Gannon E, Kobeinia R, Maynard J, Sansom J. Forearm EMG during rock climbing differs from EMG during handgrip dynamometry. Int J Exerc Sci. 2008; 1(1): 4-13.

35.Deyhle MR, Hsu H-S, Fairfield TJ, Cadez-Schmidt TL, Gurney BA, Mermier CM. Relative importance of four muscle groups for indoor rock climbing performance. Journal of Strength and Conditioning Research, 2015; 29(7): 2006-2014. https://doi.org/10.1519/JSC.0000000000000823

36. Michailov ML, Baláš J, Tanev SK, Andonov HS, Kodejška $J$, Brown L. Reliability and validity of finger strength and endurance measurements in rock climbing. Res Q Exerc Sport. 2018; 89(2): 246-254. https://doi.org/10.1080/02701367.2018.1441484
37.Wright JR, McCloskey D, Fitzpatrick RC. Effects of systemic arterial blood pressure on the contractile force of a human hand muscle. J Appl Physiol. 2000; 88(4): 1390-1396. https://doi.org/10.1152/jappl.2000.88.4.1390

38.Babault N, Cometti G, Bernardin M, Pousson M, Chatard JC. Effects of electromyostimulation training on muscle strength and power of elite rugby players. Journal of Strength and Conditioning Research, 2007; 21(2): 431-437. https://doi.org/10.1519/00124278-200705000-00025

39.Lee SEK, Lira CAB, Nouailhetas VLA, Vancini RL, Andrade MS. Do isometric, isotonic and/or isokinetic strength trainings produce different strength outcomes? J Bodyw Mov Ther. 2018; 22: 430-437. https://doi.org/10.1016/j.jbmt.2017.08.001

40.Herrero J, Izquierdo M, Maffiuletti N, Garcia-Lopez J. Electromyostimulation and plyometric training effects on jumping and sprint time. Int J Sports Med. 2006; 27: 533-539. https://doi.org/10.1055/s-2005-865845

41.Brocherie F, Babault N, Cometti G, Maffiuletti N, Chatard JC. Electrostimulation training effects on the physical performance of ice hockey players. Medicine \& Science In Sports \& Exercise, 2005; 37: 455-460. https://doi.org/10.1249/01.MSS.0000155396.51293.9F

42.Silinskas V, GrUnovas A, Stanislovaitiene J, Buliuolis A, Trinkunas E, Poderys J. Effect of Electrical Myostimulation on the Function of Lower Leg Muscles. Journal of Strength and Conditioning Research, 2017; 31(6): 1577-1584. https://doi.org/10.1519/JSC.0000000000001594

43.Jaworski CA, Krause M, Brown JJCism. Rehabilitation of the wrist and hand following sports injury. Clin Sports Med. 2010; 29(1): 61-80. https://doi.org/10.1016/j.csm.2009.09.007

44.Josephsen G, Shinneman S, Tamayo-Sarver J, Josephsen K, Boulware D, Hunt $\mathrm{M}$, et al. Injuries in bouldering: a prospective study. Wilderness \& Environmental Medicine, 2007; 18(4): 271-280. https://doi.org/10.1580/06-WEME-OR-071R1.1

45.Logan AJ, Makwana N, Mason G, Dias J. Acute hand and wrist injuries in experienced rock climbers. British Journal of Sports Medicine, 2004; 38: 545-548. https://doi.org/10.1136/bjsm.2002.003558 


\section{Information about the authors:}

Dicle Aras; (Corresponding Author); http://orcid.org/0000-0002-9443-9860; diclearasx@gmail.com; Faculty of Sport Sciences, Ankara University; Ankara, Turkey.

Selçuk Gül; http://orcid.org/0000-0003-3482-0771; selcukgul@gmail.com; Department of Sports Medicine, Erzurum Regional Education and Research Hospital; Erzurum, Turkey.

Fırat Akça; http://orcid.org/0000-0002-0764-105X; firatakca@gmail.com; Faculty of Sport Sciences, Ankara University; Ankara, Turkey.

Mehmet Gülü; http://orcid.org/0000-0001-7633-7900; mehmetgulu80@gmail.com; Faculty of Sport Sciences, Ankara University; Ankara, Turkey.

Özkan Güler; http://orcid.org/0000-0002-5713-3395; ozkanguler@msn.com; Faculty of Sport Sciences, Ankara University; Ankara, Turkey.

Cemil C. Bıldırcın; http://orcid.org/0000-0003-2423-9182; ccbildircin@gmail.com; School of Physical Education and Sports, Çukurova University; Adana, Turkey.

Erşan Arslan; http://orcid.org/0000-0002-2933-6937; ersanarslan1980@hotmail.com; School of Physical Education and Sports, Siirt University; Siirt, Turkey.

Güney Çetinkaya; http://orcid.org/0000-0002-1757-5105; guneycetinkaya@gmail.com; Faculty of Sport Sciences, Akdeniz University; Antalya, Turkey.

\section{Cite this article as:}

Dicle Aras, Selçuk Gül, Fırat Akça, Mehmet Gülü, Özkan Güler, Cemil C. Bıldırcın, Erşan Arslan, Güney Çetinkaya. Four-week of local electromyostimulaiton training on fingerboard increases the isokinetic wrist strength and endurance. Physical Education of Students, 2020;24(3):127-134.

https://doi.org/10.15561/20755279.2020.0301

This is an Open Access article distributed under the terms of the Creative Commons Attribution License, which permits unrestricted use, distribution, and reproduction in any medium, provided the original work is properly cited http://creativecommons.org/licenses/by/4.0/deed.en

Received: 12.02 .2020

Accepted: 15.03.2020; Published: 30.06.2020 